\title{
Delivering "Virtual Ethnicity" Drama: A Pedagogical Design For Bridging Digital And Diversity Barriers
}

\author{
E. Vincent Carter, Ph.D., California State University, USA
}

\begin{abstract}
This study examines an original dramaturgical method for creating virtual world experience called virtual world drama. The instructional focus is improving students' aptitude for analyzing ethnic identity by instilling both conceptual and multicultural competency. An exploratory research method is used, relying on observation (disguised and non-disguised) and survey information collected from a student sample spanning four academic quarters. Findings suggest that virtual world drama deepens the specificity of ethnic culture analysis and broadens the spectrum of ethnic culture awareness. In addition learning outcomes are evaluated based on improvements in ethnic aptitude collaboration, competence, and community.
\end{abstract}

Keywords: Marketing Education; Digital/Online Pedagogy; Virtual Worlds; Virtual/Digital Ethnicity; Dramaturgy; Multicultural Education; Ethnic Diversity

\section{A WONDERFUL VIRTUAL WORLD FUTURE FOR MARKETING EDUCATION}

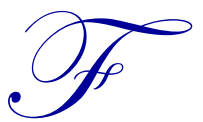

uture marketing educators will frequently venture into virtual worlds to prepare students for innovative marketing practices (Wood 2011; Twining 2010). A promising research stream has sprouted to advance virtual world marketing strategies (Wasko, et al. 2011; Liu, et al. 2007), analyze consumption experiences (Denegri-Knott and Molesworth 2010; Wood and Solomon 2009), and align real/virtual brand engagement (Daugherty, et al. 2008; Molesworth 2006; Castronova 2005). Marketing educators must stay abreast of these trends to deliver relevant and realistic virtual world pedagogy (Wood 2010). In the marketing education literature, Wood, et al. (2008a) defines virtual worlds" as; "3-D computer mediated environments that offer rich visual interfaces and real-time communication with other residents." Virtual world learning is on the leading edge (Messinger, et al. 2008) of an expanding continuum of digital marketing curricula (Wymbs 2011, Buzzard, et al. 2011). It equips marketing educators to deliver experiential learning with 3-D simulations of market environments such as Second Life (Baker, et al. 2009; Salmon 2009; Enright 2007) and autonomously designed human avatar personae (Suh, et al. 2011; Hemp 2006; Schroeder 2002). As the leading edge in Web 2.0 and social media instruction (Tuten and Solomon 2013; Kaplan, et al. 2010; Cronin 2009), virtual world learning completes the paradigm shift from "traditional teaching to technology-based education" (Evans 2001).

More precisely, virtual world pedagogy extends the pattern of fusing cognitive sensing with computer systems that typifies online instruction. As Figure 1 shows, the application of online digital themes in marketing courses evolves from simple learning outcomes like finding online information (access), to more tactical techniques for facilitating online market interaction through blogs, webcasts, chat-rooms, and social media like Facebook (agency). Beyond the capability of these online access tools, marketing educators have begun to employ online applications that impart strategic digital intelligence (acumen). For instance, online data-mining, customer relationship, project management, logistics planning, and media placement functions are increasingly used to support marketing course objectives. At each stage, the difference between digital computers and human cognition becomes less distinct. Now, with the parallel reality of virtual worlds (artificial), marketing educators can explore immersive 3-D environments comprised of computer animated atmospheres and cognitively activated avatars. 
Figure 1. The Evolution of Online Digital Technology in Marketing Education

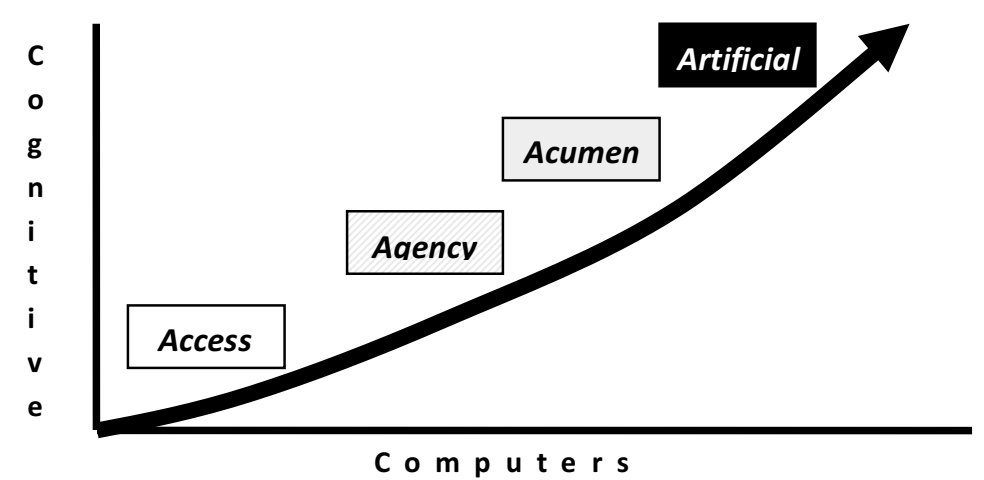

Although marketing educators clearly value digitally literacy, they have only begun to envision digital life. Significant inroads have been made in realizing the pedagogical benefits of online interactive technology (Spiller and Scovotti 2008; Ueltschy 2001). Yet, the adoption of artificial virtual world course designs lags in comparison to applications of other digital techniques. Wood, et al. (2008a) defines virtual worlds" as; "3-D computer mediated environments that offer rich visual interfaces and real-time communication with other residents." Like those authors, this study exposes marketing educators to the viability of virtual worlds for course pedagogy. As a prescient commercial marketing practice and pliable curricular marketing platform, virtual worlds can support a variety of course learning outcomes.

Commercially, virtual world technology is transforming business enterprise and marketing strategy. Animated online environments are deployed to guide innovation, gather intelligence, and gain strategic social media marketing advantages (Tuten and Solomon 2013; Tuten 2010). The popular online forum "Second Life" alone is estimated to have more than 20 million "residents" spending millions of U.S. dollars daily (Kaplan and Haenlein 2009; Enright 2007). Fortune 500 companies have invested nearly $\$ 2$ billion to establish brand presence in this globally accessible virtual world market (Kirkpatrick 2007; Rymaszewski, et al. 2006). These trends impact real and virtual world marketing because avatars (artificial 3-D personas) acquire social identity (Wood and Solomon 2009) which influences the behavior of both actual and artificial customers (Holzwarth, et al. 2006; Suh and Lee 2005; Catterall and Maclaran 2002). Virtual world marketing simulations have successfully been used to improve marketing strategy, retail merchandising, brand loyalty, animated product placement, and customer research (DrakeBridges, et al. 2011; Tikkanen, et al. 2009; Shang, et al. 2006; Moleswarth 2006; Ederly 2006; Klein 2003; Li, et al. 2002). The real world benefits of analyzing virtual world identity is evident in McGoldrick, et al.'s (2008) typology of avatar roles.

Curricular virtual world presence is growing as well. Dozens of international universities presently offer virtual education platforms, ranging from online course delivery to immersive animated learning environments (Wood, et al. 2008a). Marketing educators currently have access to 3-D animated simulation courseware such as "VLearning" offered by the online education training company Vertical Learning Curve (VLC) www.vlcglobal.com. The diffusion of digital education offerings is being led by both top-down administrative decisions to stake virtual world claims (Solomon, et al. 2009) and by bottom-up innovation among individual faculty members experimenting with virtual world course applications (Wood and Suter 2004). Animated avatar personae afford unique learning possibilities for examining relationships between individual identity and collaborative interaction in realistic 3-D environments (Kritz and Shonfeld 2012). Thus, virtual world technology platforms are spurring pedagogical innovation across all fields of study (Twining 2010; Baker, et al. 2009; Dickey 2003).

In terms of precise marketing education objectives, virtual world instruction can improve students' ability to think critically about concept application, analyze market participant identities, and evaluate patterns of market interaction. Virtual world potential for marketing education has been largely inspired by Natalie T. Wood, culminating with a "Marketing in Virtual Worlds" textbook (Wood 2011) and founding the Association of Virtual Worlds, to pursue social, strategic, and scholastic goals. Similar pioneering efforts to couple virtual worlds and marketing education are made by Michael R. Solomon (Solomon and Wood 2009; Solomon, et al. 2009; Wood, 
Solomon, and Allan 2008) and Tracy L. Tuten (2009, 2010). They show how to derive real world learning experience from virtual world environments.

However, several hurdles can be found along this promising path virtual world instruction. Within this evolving set of virtual world instruction impediments two key pedagogical problems for achieving desirable marketing education outcomes are limited instructional technology and multicultural familiarity - including low ethnic diversity in marketing courses. Smart classroom facilities, including mobile device platforms, are optimal for students to fully simulate immersive 3-D market interactions. Likewise, students' cultural familiarity contributes to avatar identities and creates more adept virtual world interactions.

In order for virtual world pedagogy to further marketing concept proficiency, critical thinking, and pattern analysis, students must be provided with both the digital means and the multicultural meanings for virtual world participation. Yet, the practical reality for many marketing educators is that neither the digital window nor the multicultural mirror is available. In these instances, marketing educators and students miss an opportunity to explore an increasingly vital digital marketing domain. This study reports on a consumer behavior course innovation that customized dramaturgical methods to bridge the virtual world barriers of technology facilities and ethnic familiarity.

\section{Learning Paradox: Exploring Virtual Worlds without Ethnic Walls}

Many marketing education classrooms are not equipped with instructional technology to deliver 3-D virtual world content to an entire class of students - including mobile and social media applications. Also, the physical classroom design and furnishings impact the conduciveness of technology systems. Even at universities with digital 3-D media accommodation, low computer literacy poses another challenge to curricular virtual world adoption. Therefore, virtual world exposure in marketing education courses is deterred by inadequate instructional technology accommodation (computer systems and classroom space), as well as by insufficient computer literacy abilities. Both of these virtual world instruction deterrents are outside of the marketing educator's authority, control, and perhaps capability. However, dramaturgy permits students to become vicariously immersed in virtual world environments, through theatrical staging (See Figure 2).

Figure 2. Dramaturgy Bridges Virtual World Barriers and Ethnic Wall Boundaries

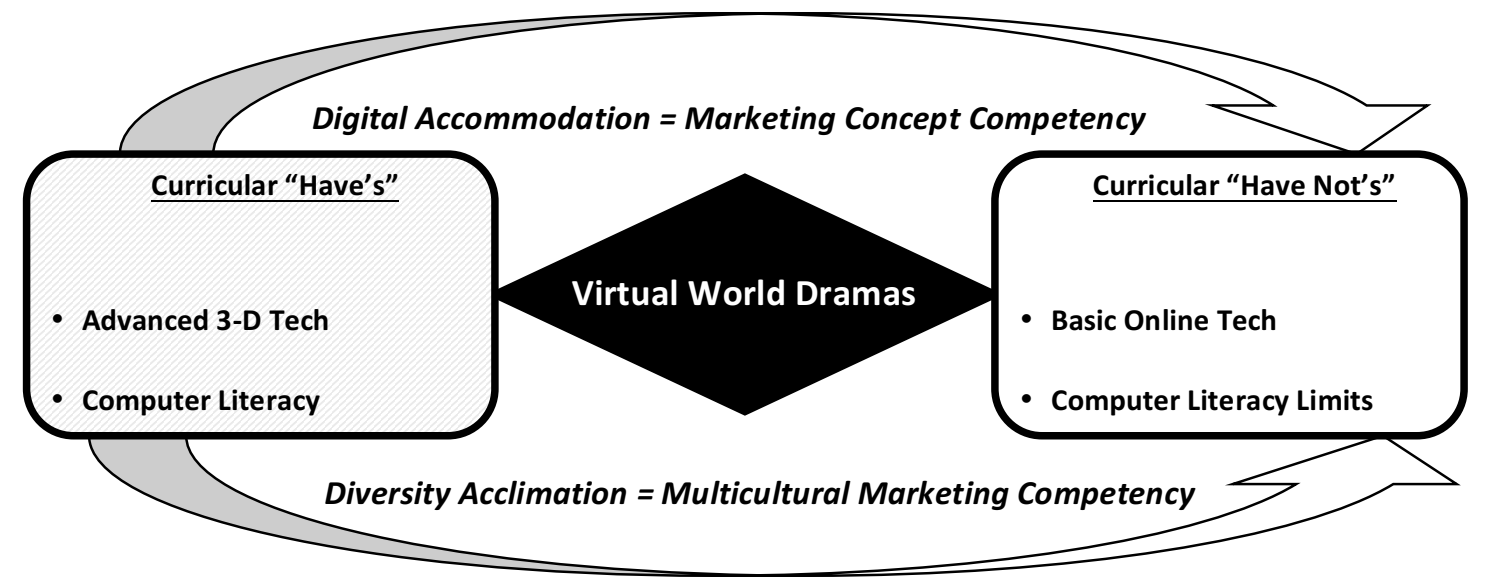

Consumer identity is central to marketing's customer orientation ethos. Marketing education courses are anchored and cohered by the analysis and profiling of consumer characteristics. In the marketing classroom, students usually welcome the opportunity to tap their personal experiences as consumers as a source of conceptual knowledge. This capacity for personal self-reference is also essential to learn marketing skills through virtual world instruction. Unfortunately, ethnicity/race -- including foreign nationality -- is among the most difficult consumer identity trait for students to discuss. The marketing education literature affirms this discomfort in learning dialogues, regarding the topic of American ethnic groups (Carter 2010; Cherrier, et al. 2006; Jones 2003) as well as the tendencies of foreign nationalities (Payan, et al. 2010). Besides having personal concerns stemming from limited 
ethnic familiarity, the risks of violating codes of "political correctness" engender reluctance among students to discuss multicultural attributes. This hesitancy hinders students' marketing aptitude because markets are increasingly multicultural, with ethnicity as a primary consumer behavior influence.

Ultimately, the range of ethnic awareness and acclimation among students determines the richness of multicultural marketing competency that can be imparted through instruction. Yet, in order to acquire these insights students must have a comfortable way to transcend ethnic walls. Projection techniques used in drama for character development (Martin, et al. 2002), and marketing research for psychological discovery (Edmunds 1999) can lessen the sensitivity of ethnic subject matter. Thus, dramatic virtual world portrayals solve the ethnic transcendence paradox to impart multicultural marketing competency.

\section{Course Innovation - Dramaturgical Learning Design for Virtual World Education}

As an extension of curricular research, this study highlights a virtual world course module designed using a dramaturgical pedagogy. Role play scenarios allow students to profile avatar identities and plot their virtual world interactions. This conceptually grounded avatar profiling exercise is intended to improve students' consumer analysis aptitude. Consumer analysis is defined as an ability to apply to interpret dimensions of individual identity. Typically described as "Individual Consumer Influences" (Blackwell, et al. 2006), this sequence of concepts form a foundation for designing virtual consumer avatars and developing students' consumer analysis. Specifically, to learn how segmentation variables, motivation states, as well as core beliefs, feelings, and attitudes influence consumer behavior.

\section{Ethnicity Focus}

Ethnic identity is isolated as the underlying analytical focus because of its prominence in consumer behavior and paucity in the virtual world marketing education studies to date.

"Ethnicity is an important element in determining culture and predicting consumer preferences and behaviors. It is a process of group identification in which people use ethnic labels to define themselves and others." (Blackwell, et al. 2006, 447).

Yet, the course delivery of the virtual world module does not emphasize ethnicity, or any particular identity trait. Students are instructed to participate in the virtual world scenario as a way of analyzing consumer behavior patterns by applying fundamental course concepts. A valid guide can be offered for students' composition of avatar profiles and virtual world activities, because consumer behavior textbooks and the marketing literature contain extensive descriptions of authentic consumer identity traits and actual market interaction tendencies (Beverland and Farrelly 2010; Solomon 2012). However, history, sociology, psychology, and cultural anthropology material is readily accessible online.

In this manner, the "virtual ethnicity" study is administered using disguised observation. The instructor covertly records the composition of avatar identity traits and tendencies exhibited during virtual world market interaction. Collaborative multicultural interaction among avatars in the scenario, and students in class, provides a unique educational setting for observing the formation of "virtual ethnicity." Then, using a questionnaire framed according to course concepts, student responses are checked for comments about ethnicity. Although this study probes ethnic identity, dramaturgical modules in marketing courses can be used to examine a variety of avatar characteristics (e.g., gender, age, social class) and virtual world activities.

Instructionally, access to ethnic history reference sources (Dinnerstein and Reimers 2008; Koslow and Salett 2003; Costa and Bamossy 1997; Goldberg 1995; Tonkin, et al. 1989), contemporary multicultural publications (Humphreys 2011; Yankelovich 2011), and the multicultural marketing literature (Rao 2006; Pires and Stanton 2005; Burton 2005, 2002; Xu 2004; Cui 2001), provides authentic course materials to cultivate students' ethnic identity analysis aptitude for real world and virtual world markets. A natural dialectic occurs between ethnic cultural identity and interaction with multicultural brand marketing (O'Reilly 2005) - whether real, virtual, or dramatic. As an avatar profile attribute, ethnic identity is defined for students as encompassing both a set of common collective 
cultural traditions (e.g., values, language, customs, and symbolic expressions) and a distinctive set of individual traits (e.g., genetic, biological, inherited). These guidelines encourage students to compose authentic avatar profiles with ethnic unity and diversity (Mich and Keillor 2011).

These virtual world module considerations echo Atwong, et al's. (2002) study of ethnic influences in the online learning experience. However, tracing the path of Wood, et al. (2008b) the learning focus is on ethnicity as a personified virtual world property (Carter 2011; Carter 1996). Wood is noteworthy in her parallel study of virtual worlds and ethnic cultural influences (Wood 2012, 2011; Wood and Solomon 2009; Munoz, Wood, Cherrier 2006; Wright Lego, Wood, Solomon 2002). Besides engendering multicultural inclusion in course learning (Carter 2010; Yoo and Donthu 2002), "virtual ethnicity" is an open digital construct for collaboratively combining ethnic traits and traditions (Carter 2011; Dou, Yoo, and Liangyu 2003).

Allowing students to freely and fluidly compose avatar persona endows ethnicity with a far more malleable set of properties in virtual worlds than possible in the real world. Still, this liberated premise of "virtual ethnicity" for composing avatar personae is solidly grounded in the critical theory of ethnicity as a dynamic combination of complex cultural meanings (Jamal 2005, 2003; Burton 2002; Penaloza and Gilly 1999; Venkatesh 1995). Like Briley, et al. (2000), "virtual ethnicity" is a dynamic carrier of identity that is cultivated by the collaborative decisions afforded by virtual worlds.

\section{Dramaturgical Framing}

In this study, a dramaturgical pedagogy guides the virtual world scenarios used to simulate avatar role play. Students discover deeper layers of avatar identity by scripting a drama of virtual world interactions. Unfortunately, the course module was limited by the same technology, time, and training constraints that challenge other marketing educators interested in virtual world instruction. As a practical response to these constraints, dramatic real world participation is used instead of immersive virtual world presence. Students rely upon cognitive simulation to imagine the vivid animation experiences of actual virtual world presence. Drama guidelines are instrumental in explaining and executing these creative visualization and role projection techniques. In addition to simulating virtual world experiences, drama techniques like projective role play with fictional scripts can also reduce students' hesitancy to converse about personal consumer behavior topics like identity, self-concept, ethnicity, gender, or social class.

Goffman (1959) coined the term "dramaturgy" to develop a micro-sociological theory for analyzing the context and not the cause of personal interaction. By extending the Shakespearean principles of Edward Burke's classical analysis of theater roles (Brissett and Edgley 1990), Goffman developed dramaturgy into a practical method for observing that "all the world's a stage" (Bullen 2012; Adams 1963). Like actors on stage, human identity is shaped by motivations for interacting with others, objects, and occasions. Accordingly, dramaturgical plots reveal personal identity through purposeful interaction. Virtual world presence is analogous to theater performance, with cast of characters, scenes, set and props. It stands to reason that Goffman's (1959) dramatic plotting of real world social interaction would help script virtual world marketing pedagogy and practice.

Dramaturgy has also proven to be adaptable to virtual world technology. Since framing computer-user interface as theater performance with personal identities (Turkle 1997; Laurel 1991), the elements of drama have directed digital dialogues. Present day virtual world experiences are delivered through dramaturgical techniques like character development, narrative scripting, and scene designs (Moore, et al. 2008; Ryan 2001; Anstey, et al. 2000; Jennings 1996).

In business education dramaturgy is a course design that allows students to act out organizational roles in case studies, simulations, or theatrical exercises (Boggs, et al. 2007; Leberman and Martin 2005; Huffaker and West 2005; Gibb 2004; Karreman 2001). Lauded as a student-centered course design (Finan 2004), dramaturgy bridges the classroom and company divide (Halliday 2008; Pearce 2004). For that reason, dramaturgy is an ideal pedagogy for virtual world instruction because it is aligned with what Sautter (2007) describes as "mode of delivery and structure." The potential of dramaturgy for marketing education is epitomized by both Finsterwalder and O'Steen's 
(2008) "Marketing Theater Model" as a creative guide, and Mosio and Arnould's (2005) shopping experience framework as a constructive goal.

Studies involving digital participation in virtual world are nascent in marketing education literature. Wood (2008) pioneered the design of truly "immersive" virtual world education and, like others (Solomon, et al. 2009; Tuten 2009; Wood, et al. 2009), find that the learning benefits warrant expanded instructional application. Although this module substitutes dramatic performance for digital presence, virtual world experiences are aptly replicated in a manner similar to the classroom simulation of marketplace interaction of Russell-Bennett, et al. (2010).

\section{Course Implementation - Multicultural Learning Delivery of Virtual World Role-Play}

The virtual world module was administered for four academic quarters at an undergraduate consumer behavior course at a regional American university. Similar to theatrical productions, the virtual world drama is implemented through a process of preparation instruction and performance interaction.

\section{Preparation Instruction}

Absent the resources to deliver a virtually immersive experience, students are oriented to the module with entertaining videos that explain virtual world environments and avatar engagement. In addition, the class is shown how to create actual virtual world presence using a 30 minute "free-trial" on the Second Life website (Rymaszewski, et al. 2006). Usually, several students will have personal experiences to share regarding virtual worlds, and these are integrated into the orientation as well. Following this contextual orientation, students are divided into teams of 5 to 7 students. Besides adhering to ethical conduct, as well as agreeing to use valid consumer, marketing, and sociocultural facts, no boundaries are placed on the avatar profiles.

Conceptually, consumer analysis aptitude is introduced to students as a heuristic for 'peeling the layers' of individual identity. An "egg-layers" diagram is presented as a heuristic to guide for composing and analyzing avatar profiles. Like an egg, the "individual consumer influences" chapters (Blackwell, et al. 2006b) progress from a consumer "shell" of explicit/observable segmentation variables (e.g., demographic, geographic, psychographic, behavioral), through the mediating "white" of implicit/operative consumer motivations, to the inner "yolk" of intrinsic/original consumer beliefs, feelings, and attitudes (See Figure 3).

Figure 3. Egg-Layers Diagram of Consumer Identity Concepts

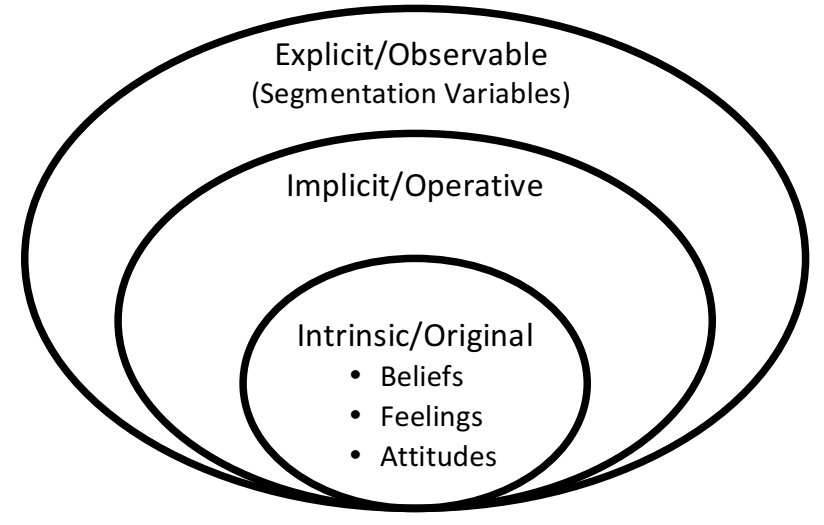

Dramatic virtual world portrayals enable ethnic projections of both the real and ideal self (Wood, et al. 2003). Avatar profiles adapt consumer identity concepts to diverse ethnic characteristics and cultures. Solomon and Wood (2009) ply the entire range of customer behavior concepts to social identity in virtual worlds. So, the instruction phase raises consumer analysis aptitude by preparing students to create virtual world scenarios (dramaturgy) and conceptually profile identity ("egg-layers" diagram). 


\section{Performance Interaction}

The dramaturgic scenario is presented as a realistic simulation of virtual world presence. Students compose avatar profiles and perform scripts as if they are immersed in animated virtual worlds. Virtual world simulations, whether digital or dramatic, are more malleable because avatar profiles are designed whereas real world consumer profiles are already determined.

Avatar Identity Analysis - “Egg-Layers” Concepts

Although student teams initially specify motivations, as well as beliefs, feelings, and attitudes, those implicit and intrinsic ethnic identity properties are revised and validated based on avatar script interactions. Segmentation variables address observable ethnic identity descriptors like race, residence, education, occupation, income, spending, household composition, lifestyle activities, and consumption preferences. Maslow's Needs Hierarchy (Maslow 1970) is used to associate motivational drives with ethnic identity descriptors. For instance, physical needs could drive consumer behavior related to ethnic food, fashion, or furnishings. Security drives can reflect geographic tendencies associated with ethnic neighborhoods. Social needs signify ethnic community rituals and interactions. Esteem needs account for educational, professional, and personal standards of achievement - which vary among ethnic groups as do exemplars of success. Self actualization is revealed in avatar drives based on higher ideals. These ethnic ideals are central to cultural narratives that express beliefs like freedom, peace, and unity.

At the deepest level of ethnic identity the avatar profile addresses specific beliefs, feelings and attitudes (BFAs). These BFAs set the threshold for middle layer motivations, as well as how ethnic identity is individually and collectively defined. Studies attribute BFA profiles to consumer's "felt ethnicity" and the "intensity" of ethnic affiliation (Williams and Qualls 1989; Deshpande, et al. 1986). However, during the module, students' adopted more individualized ethnic BFAs that were culturally transcendent and resemble "situational ethnicity" (Stayman and Deshpande 1989). This fluid yet valid approach for composing and understanding ethnic identity as an inclusive multicultural mosaic is characterized as "universal" (Carter 2010). Indeed, virtual avatars are citizens of the world.

\section{Avatar Interaction Analysis - Dramaturgy Context}

A simple script allows for ample improvisation within the main plot. As a result, avatar interaction is generated by both planned scenario roles and spontaneous in-class exchanges. By balancing the planned and spontaneous features of avatar script interaction, instructional continuity is maintained throughout the module. The planned script provides a collaborative agreement on the overall scenario theme, sequence of acts, as well as plot direction. Once that standard narrative is in place, students are able to prepare for their avatar's role in the script and create dialogue. The virtual world scripts progress from an opening acquaintance with each avatar, to a shared moment of realization among avatars, and an ending that completes the discovery narrative. The templates used to script avatar interactions portray simple plots with recognizable roles in realistic relationships. Simplicity also keeps consumer concepts clear and makes it easier for students to enact interaction scenes.

These narrative guidelines are captured by the virtual world script titles for each quarter - "Two Couples on a Vacation" (See Figure 4). The scripts are not directly related to ethnicity, because students are not instructed to emphasize any particular aspect of the avatar profile. Supporting the main plot, are a sequence of tailored content video links is woven through the script to create a visually entertaining atmosphere. The links provide entertaining videos of the locations, social venues, and market encounters that comprise each virtual world scenario. 
Figure 4. Sample Virtual World Module Script Template

“2 Couples on a Vacation”"

Orientation: Exposure to online virtual world video links:

Virtual Worlds (overview) --

http://www.youtube.com/watch?v=Z7C6LAEQUGs

http://www.youtube.com/watch?v=O62GHcIVKS4

http://www.youtube.com/watch?v=0CijdlYOSPc

Avatars (explanation) -- http://www.youtube.com/watch?v=9hte2MJ54CA

Second Life (introduction) -- http://www.youtube.com/watch? $=$ LraV05R $2 \mathrm{~m} 50 \&$ feature $=\mathrm{relmfu}$

Second Life (customization) -- http://www.youtube.com/watch?v=z3gHCupXSMs

Second Life (experience) -- http://www.youtube.com/watch? $=\mathrm{GgNcTxgCMLQ} \&$ feature $=\mathrm{relmfu}$

Second Life (marketplace) -- http://www.youtube.com/watch? $\mathrm{v}=4 \mathrm{cvmTdoru} 1 \mathrm{I} \&$ feature $=$ relmfu

Second Life (social networks) --http://www.youtube.com/watch? $\mathrm{v}=\mathrm{tHx} \quad$ AVAsD0\&feature $=\mathrm{relmfu}$

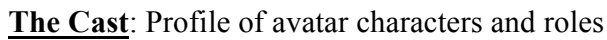

Scene 1 - "The Meeting"

During their pleasure trip airline flight, a liberated Hispanic American couple, Juan and Lupe unexpectedly encounter an intriguing women traveling to join her enigmatic mate in Barcelona Spain. After hours of conversational bonding, the three agree to spend the weekend as a foursome, in a spacious suite at The Hotel Majestic, located on Paseo de Gracia. http://vimeo.com/2026796

THE MEETING takes place in "El Prat Airport," a blend of old world Spanish culture and modern traveler amenities. http://www.youtube.com/watch?v=u-s-dl6lryk

As THE MEETING transpires, several INDIVIDUAL CUSTOMER CHARACTERISTICS (ch.7) are revealed, and BRAND preferences emerge during the vacation.

\section{Scene 2 - "The Mingling"}

Now settled into their posh Barcelona "Hotel Majestic," the Hispanic American and Swedish couple finds that a stimulating interplay exists among their varied MOTIVATIONS (ch.8). Waking after a night of drinks and chats, the foursome takes to the streets of Barcelona for a day of sightseeing. http://www.youtube.com/watch?v=Z-wyE9TjRwk Daylight Barcelona tourist activities are followed by separate nightlife plans for the romantic and spirited MOTIVATIONS (ch. 8) evoked by the atmosphere of venues suitable for a Spanish vacation memories. http://www.youtube.com/watch?v=4UcCGDQHYy4\&NR=1

\section{Scene 3 - "The Mystery \& Memories"}

Winding down after a Mediterranean weekend escape, the foursome decides to share special secrets from their couple's night out, in the more casual company of gender peers. The dialogue during these gender pairings, reveal deeply held BELIEFS, FEELINGS, ATTITUDES (ch. 10). The guys head for a rousing soccer game between Barcelona and Real Madrid, to share candid views. http://www.youtube.com/watch? $=$ ZzuF3oTh-vc

The ladies head for the balmier southern Spanish beach resort town of Marbela in Andalucia on the famed Costa del Sol (Coast of the Sun), to indulge in an authentic spa. http://video.google.com/videoplay?docid=8008085077217441442\#

Reunited at the festive restaurant La Reina del Rival, the foursome discusses the revealing Barcelona's vacation. http://www.youtube.com/watch?v=-hBWJeGbFng

Spontaneous avatar interaction occurs in a similar manner as would jazz improvisation on a standard melody. As long as actions and dialogue are true to the avatar profile and main plot, students are allowed the freedom to innovate. Familiar scenarios with enjoyable interactions between avatars and fun scenes raise student involvement. In turn, personal involvement motivates students to be imaginative - especially when creating spontaneous dialogue. This light hearted exploration of avatar identity through spontaneous interaction helps students bond and become acclimated to the dramatic learning process.

\section{Course Insights - Instructional Lessons Discerned from Virtual World Drama}

Overall, the findings suggest that a dramaturgical context is effective in motivating students to become vicariously immersed themselves in the malleable virtual world experience. As a result, the virtual world dramas 
improved application of core consumer behavior concepts, as well as increased the analytical accuracy of consumer identity profiles and interaction patterns. In particular, the virtual world dramas raised students' aptitude for composing and comprehending ethnic consumer/avatar profiles. Because this study focused on ethnicity as an identity characteristic, an original property labeled "virtual ethnicity" emerged as an extended self concept that was projected by students onto virtual world avatars. Negroponte (1995) lays the digital human identity foundation for asserting "virtual ethnicity" as an important affordance in virtual world pedagogy and practice (Dickey 2003; Li, et al. 2001). Likewise, Sherry (2000) culls together the antecedents for advancing "virtual ethnicity" in digital avatar representation.

For the virtual world dramas, students were arranged in groups to observe ethnic collaboration in the composition of avatar profiles, as well as in real world class participation. These collaborative virtual world dramas were found to deepen the specificity of students' ethnic culture analysis and widen the spectrum of students' ethnic culture access. Analytical depth pertains to complete conceptual alignment as well as correct cultural authenticity. Awareness breadth pertains to the fluidity with which transference occurs between students' own ethnic identity and other ethnic cultures.

\section{Qualitative Improvement Measures}

The virtual world dramas made pedagogical improvements based on three learning indicators; a) consumer identity analysis aptitude, b) virtual world marketing comprehension and c) multicultural/ethnic marketing proficiency. These three qualitative measures are already mentioned throughout the description of introduction and interaction phases. Consequently, the insights discussed here reinforce the fundamental improvements with a review of ethnic virtual world discoveries. Little consideration has been given to multicultural/ethnic aptitude in the virtual world marketing literature, either to design avatar identity or depict virtual world interactions. Although the purpose is to study "virtual ethnicity," students are only directed to compose avatar profiles for consumer analysis -- without any emphasis on ethnicity.

\section{Quantitative Improvement Measures}

In addition to disguised observations during the module, "virtual ethnicity" insights come from probing students' responses to questions upon completion of the script. Like the dramaturgic module design, this postmodule questionnaire calls upon students "reflective" skills of cognitive visualization (Peltier, et al. 2005). The instrument is distributed as an assignment addressing the consumer analysis of real world versus virtual world identity. Figure 5 presents the assignment instrument and the ethnic profiles of students and avatars. These questionnaire responses are interpreted as exploratory qualitative findings and results are summarized as collective content patterns rather than as descriptive data. 
Figure 5. Virtual World Group and Individual Student Questionnaire Instrument

\section{A. GROUP RESPONSE INSTRUMENT - Sizing the Scenario Script}

How did demographics, psychographics, motivation, and beliefs/feelings/attitudes impact the initial and closing aspects of each scene? (Specify reasons for ratings based on avatar identity and interactions)

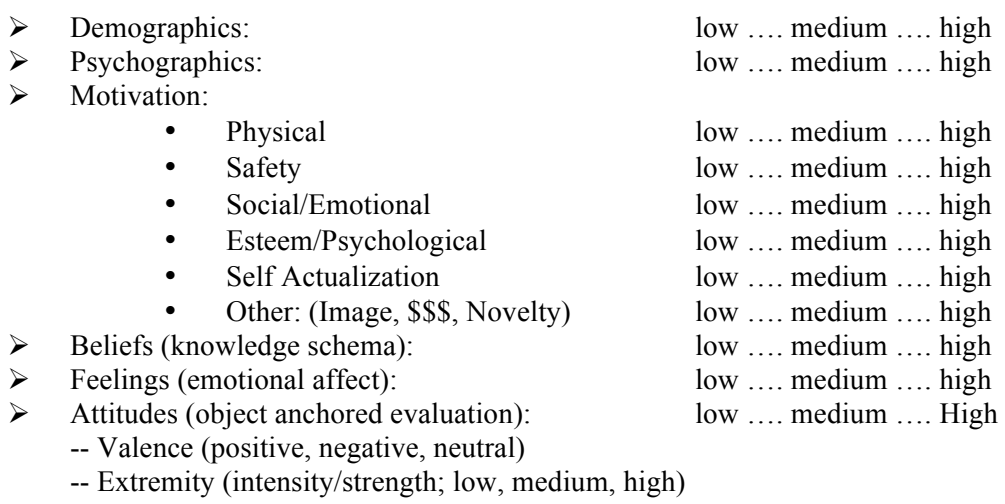

\section{B. INDIVIDUAL RESPONSE INSTRUMENT -- "Real World" \& "Virtual World" Relationships}

Discuss the adaptation of your PERSONAL PROFILE to the AVATAR PROFILE, based on the "egg-layers" model of individual consumers, based on an outer egg shell comprised of chapter 7 factors (demographic, geographic, psychographic, behavioral), a middle egg white layer composed of chapter 8 motivations, and an inner egg yolk of chapter 10 beliefs, feelings, attitudes.

1) List your personal traits and describe how easy/hard was it to think of your self with the avatar's GEODEMOGRAPHIC profile?

2) List your personal traits and describe how easy/hard was it to think of your self with the avatar's PSYCHOGRAPHIC (lifestyle) profile?

3) List your personal traits and describe how easy/hard was it to think of your self with the avatar's MOTIVATION profile?

4) List your personal traits and describe how easy/hard was it to think of your self with the avatar's BELIEF, FEELING, and ATTITUDE profile?

5) Explain how your personal BEHAVIORAL profile (purchases/uses) is affected by playing the avatar role. Are you more likely to consume differently than before playing the avatar role? Would a prolonged virtual world experience have a stronger affect on your personal consumption patterns?

6) Explain how the design of a personal avatar for your own virtual world experience could indicate certain "real world" BEHAVIORAL preferences? (physical traits, lifestyle, geography, brand motives, etc.)

The first section gathers group responses to permit shared reflective learning on consumer behavior identity concepts outlined by text chapter headings. These responses directly assess the correctness of conceptual competence, while requiring critical thinking skills to discern the relevance of particular theories to the enacted virtual world drama. By far, the most revealing finding over the four quarters of administering the virtual world drama is the extremely high significance of beliefs, feelings, and attitudes versus motivations or demographics/psychograhics. Motivations were rated second highest, with higher level Maslow drives (e.g., social, esteem, self-actualization) proving strongest. Also, psychographics were viewed as having more impact than demographics. Stated in terms of the "egg-layers" model, "intrinsic/original" avatar identity factors have greater overall relevance to patterns of virtual world drama interaction than "implicit/operative" and "explicit/observable." Likewise, "implicit/operative" factors are more meaningful than "explicit/observable", and observable explicit traits (demographics) rated lower than less observable explicit aspects (psychographics).

By contrast, responses to the individual section of the virtual world drama questionnaire consistently show a greater tendency for students to vicariously alter the outer "egg-layers" of their own self-concept based on their avatar identity profile. Although a high level of involvement with selected avatar profiles was common, students 
found it easier to adopt different "extrinsic/observable" identity traits (demographics/psychographics) than either "implicit/operative" or "intrinsic/original" attributes. There was a general consensus among students that seeing themselves with a different ethnic, gender, age, education, occupation, social, and political identity was easier than adopting different motivations or new beliefs/feelings/attitudes. Despite widespread agreement that inner levels of the "egg-layers" model are more significant to their avatar's virtual world drama interactions, students primarily internalized the outer level profile of their avatar's identity.

With respect to the ethnic research, as well as "virtual ethnicity" properties, these findings indicate a high level of identification with tangible ethnic cues that are encountered in society and media, but a low level of identification with intangible ethnic culture that is experienced within one's self and mind. Notwithstanding students' complete embrace of accurate "virtual ethnicity" traits, there was incomplete embodiment of authentic "virtual ethnicity" tendencies. Clearly, the virtual world drama context, duration, and arrangement are logical reasons for this outcome.

Taken together, the group and individual questionnaire responses show strong construct validity for consumer identity theory and high content validity for virtual world terminology as a result of the course module. Consequently, "virtual ethnicity" properties, which combine virtual world content with ethnic identity concepts, are viable for marketing pedagogy and practice.

The willingness of students to embrace diverse ethnic avatar identities is further represented by observational data. Since these student and avatar ethnic profiles are charted as descriptive discrete variables, the observed frequencies are reported quantitatively with comparative analysis using ANOVA statistics. Figure 6 presents the ethnic profiles of students and avatars using the two tables on top, as well as statistical ANOVA results in the bottom table. 
Figure 6. Profile of Virtual World Drama Student Participants and Avatar Personas with ANOVA Statistics

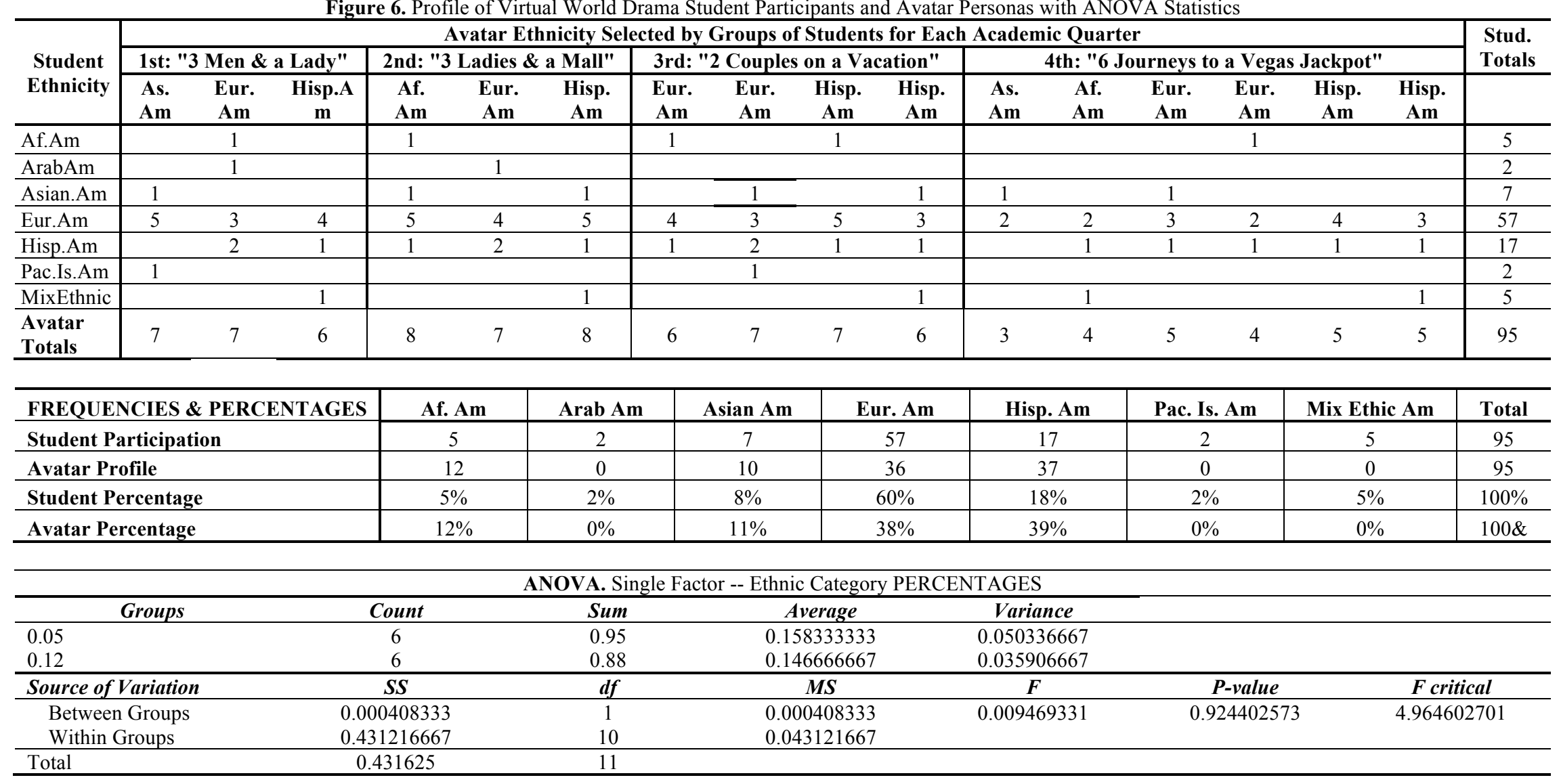


The first frequency table shows the actual ethnic identity of students comprising groups over the four virtual world drama quarters, as well as the ethnicity of their chosen avatar. This group composition chart depicts the pedagogical benefit of both real world ethnic collaboration among students and virtual world ethnic exploration through avatars attributed to the virtual world drama arrangement. Of course, this benefit is imparted using disguised observation of ethnic interaction and interest. The second table tallies the ethnic identity of students participating in the virtual world dramas and students' choice of particular ethnicities for group avatar profiles. These data are shown as frequencies and percentages.

The third table shows the results of an ANOVA test conducted by assigning the students' actual ethnicity to one sample and the students' avatar ethnicity to a second sample. The ANOVA test and F statistic (0.009469) demonstrates that the variance between the two assigned samples is statistically significant with a 92.4 percent probability. In other words, significant diversity is shown in students' willingness to select avatars with a different ethnicity than their own, despite the limited ethnic diversity among actual students in the course.

This ANOVA test affirms the capacity of virtual world dramas to enhance the breadth of ethnic exposure. This willingness to explore the multicultural spectrum for avatar identity profiles may suggest that "virtual ethnicity" is more fluid in educational settings than the largely unchanged consumer traits examined by Belisle and Bodur (2010). Again, ethnicity was selected for analysis using disguised observation because students were instructed to compose complete avatar identity profile characteristics.

\section{Theoretical Insight Meanings}

Based on qualitative and quantitative virtual world drama findings, five 'virtual ethnicity' property vectors emerge to complement Wood, et al.'s (2008a) virtual world project stages.

a) Depth -- composing correct and complete ethnic identity on 3 "egg layers" levels

b) Fluidity - awareness of and exposure to diverse ethnic cultures.

c) Collaboration - shared group discovery of ethnic identity and interaction

d) Competency - the analytical skill of designing and diagnosing "virtual ethnicity"

e) Community - participation in online virtual worlds or avatar-based social networks.

"There are four main stages to building a Second Life program from seeding initial interest through to project completion: 1. Cultivation: Inspiring potential users about the opportunities using Second Life for education. 2. Focus: Defining projects with specific timetables, requirements, technology assessments and outcomes. 3. Training: Providing adequate and ongoing training including orientation, standards, hands-on and in-world instruction, leading to comfort level proficiency, and 4. Community: Supporting the social aspects of the experience."

(Ken Hudson in Wood, et al. 2008a).

Depth pertains to students' ability to compose ethnic identity on the three levels: (a) segmentation variables, (b) motivations, and (c) beliefs/feelings/attitudes. Classroom discussions and individual student accounts confirm the instrumental role of the "egg-layers" heuristic in the development of replete and realistic avatar profiles. The completeness (conceptual alignment) and correctness (cultural authenticity) of avatar profiles determines the depth dimension. The more complete profiles led to stronger ethnic identification among students with their avatar. In addition, the more correct profiles sustainable longer ethnic interaction patterns in the virtual world script. These ethnic identity aspects of conceptual alignment and cultural authenticity are inherent in the virtual social identity construct advanced by Wood and Solomon (2009). Therefore, the depth dimension insights extend real world social gauges of "felt ethnicity" (Desphande, et al. 1986) to encompass "virtual ethnicity."

Fluidity is a function of universal ethnic perspective (Carter 2010), because it represents an open awareness of diverse ethnic cultures. The focus of this analysis is on the fluidity or transference of ethnic identity in avatar profiles. For ethnicity and other avatar traits, the virtual world scenario liberated students' willingness to explore identity profiles other than their own. The avatars' ethnic identity profile does not directly correspond with the ethnic composition of project teams. Even when virtual world avatars have a common ethnicity with one or more group members, the profiles reflect an inclusive collaborative ethnic identity approach, often resulting in avatars 
with multi-ethnic families. Wood, et al. (2003) confirms that projecting anthropomorphic traits onto avatars enables a more fluid mix of real and ideal self identity.

Carter (2010) calls this inclusive composition of ethnicity "universal" because the entire human cultural range is considered - including the often excluded European ethnic cultures and nationalities. One student's remark epitomizes this universal property, "It's like our 'virtual world' avatars transcend human identity and create a new digital ethnicity." Transcendence, perhaps, but it is only "virtual ethnicity," not a new human identity. Fluidity is affirmed by students' tendency to "crossover" (Grier, et al. 2006) or practice "culture swapping" (Oswald 1999) when choosing ethnic avatar characteristics.

This leads logically to the third factor, collaboration, which captures the social networking zeitgeist of Generation Y (Tuten and Solomon 2013; Tapscott and Williams 2005; Howe and Strauss 2000). Since students are open to multicultural experiences, network collaboration is an ideal channel to facilitate ethnic virtual world presence through the "wisdom of crowds" (Kozinets, et al. 2008). So, collaboration addresses both the dramatic classroom mode and digitally connected means for exploring "virtual ethnicity." Within the dramatic classroom mode, students are embraced by an inclusive approach towards ethnic identity and encouraged to compose "virtual world" extensions of research streams like "customer culture theory" (Belk and Sherry 2007) and multicultural marketing (Carter 2012; Rao 2006; Pires and Stanton 2005; Xu, et al. 2004; Jamal 2003; Cui 2001). Again, ethnicity is not isolated in the module's administration. Rather, ethnic guidance is provided along with literature and assistance for all avatar profile attributes. This informal supportive ethnic culture acclamation greatly improves collaborative outcomes, as gauged by the breadth of the avatars" "virtual ethnicity" spectrum and the depth of the avatars' "virtual ethnicity" specificity. Similar multicultural marketing competences are recounted by Cherrier, et al's (2006) study of collaborative activities.

Digital collaboration media distinguish immersive from imagined virtual world experience. Dramaturgy employs imagination to impart virtual world proficiency, but cannot instill immersive digital presence. Fortunately, the virtual world marketing literature offers findings regarding collaborative digital media and animated avatars. Wood, et al. (2008a) describes the digital virtual world technology as a necessary to experience the transcendence from "interactive to immersive" learning. These integrated digital technologies are described as a "matrix" (Wood, et al. 2008a), because of the overlapping social connections they introduce into the learning experience - bridging real and virtual presence. Significant training and technical assistance is required to implement digitally immersive virtual world education using animated environments like Second Life (Solomon, et al. 2009; Wood, et al. 2008a).

Fourth, "virtual ethnicity" competency can be seen as a parallel to design competency in other fields like fashion, architecture and engineering. The virtual world module enabled students to practice consumer identity modeling and thereby raise their competency for designing and diagnosing virtual ethnicity. Grier, et al. (2006) advance the idea of "ethnic embeddedness" to account for these ethnic competencies encoded into virtual world avatars and environments. In terms of designing digital content to deliver "virtual ethnicity" competency, Li, et al. $(2001,2003)$ align physical world and virtual world "affordances." Like sign posts on the mental journey to virtual worlds, digital representations of physical world characteristics point the way towards realistic experiences. Therefore, virtual affordances are the digital design ingredients for the multitude of "virtual ethnicity" recipes.

However, this increased multicultural marketing competence is not attributable to the delivery of ethnic instruction, but rather the disguise of ethnic instruction beneath the veil of composing virtual world avatar roles and scripts. In fact, this course study finds that explicit ethnic instruction might in fact impede the openness and natural expression of classroom settings, as well as the fluidity, competence, and community generated among students. This disguised cultivation of ethnic aptitude does not negate nor diminish the valuable curricular contribution of explicit multicultural marketing instruction. Rather, this study suggests that while ethnic culture principles are acquired using conventional methods, projecting ethnic identity onto fictitious virtual world avatars can help students internalize multicultural marketing competences with cognitive simulation.

Virtual world instruction can be deployed to deepen the specificity of ethnic cultures articulated by students and broaden their spectrum of ethnic cultural awareness. Course module observations for this study primarily capture American ethnic group profiles and patterns. However, virtual world course experiences have been designed 
to explore global ethnic cultures (Munoz, et al. 2006; Wright, et al. 2002), or any aspect of individual identity meaning and collective market interaction. Course observation and survey responses suggest that students' overall ethnic aptitude improved by pairing historical ethnic depth for analytical authenticity with universal ethnic breadth for adaptive awareness. Students also transfer these deeper profiles into realistic multicultural market interactions by personifying the social life of their avatars (Schroeder 2001). Virtual world module observations also highlight the importance of including all universal ethnic cultures (as either American or global ancestries) to broaden students' appreciation for ethnicity as a shared human attribute with adaptive virtual world applications.

The fifth factor, community, culminates the transformation from traditional to virtual ethnicity. The students' collaborative avatar profiling exercise can be defined as a "learning community" - within and among groups. Learning communities amplify individual knowledge through the construction of collaborative domains of expertise or practice (Kimble, et al. 2008; Wenger 1998). Marketing education scholars find that virtual learning communities enhance interactive marketing experiences (Peltier, et al. 2003), expand online knowledge transfer (Hansen 2008), improve marketing competency (Kaplan, et al. 2010), and coordinate collaborative "megaclasses" (O'Reilly, et al. 2007). Moreover, studies of "tribal marketing," "e-tribalized" social networks, and "consumer tribes" (Cova, et al. 2007; Kozinets 2006, 1999; Cova and Cova 2002) posit online communities as viable venues for collaborative "virtual ethnicity" composition. For this study, virtual learning communities raise both social capital transfer (Daniel, et al. 2003) and multicultural literacy (Nieto 1999).

\section{Instructional Implications - Virtual World Drama Contributions and Limitations}

Two primary marketing education contributions are made by this study of virtual world drama; (a) a dramaturgical pedagogy that validly substitutes and supplements digital virtual world instruction, and (b) a collaborative instructional arrangement for improving ethnic aptitude through virtual world role-play scenarios. Although these objectives are interrelated, the first, dramaturgy, is a pedagogical input, whereas the second, ethnicity aptitude, is a learning outcome.

\section{Furthering Virtual World Pedagogy}

The virtual world drama was found to be an extremely effective method for helping students to visualize core consumer behavior concepts. Instead of textbook study and expert lectures, students were freed to construct their own virtual marketplace environment using dramatic imagination as a substitute for digital immersion. This participation in assembling the material for a virtual world drama provided students with greater insight into the meanings of course concepts involved the construction of scenes and scripts. Once the virtual world drama was enacted, students applied critical thinking to determine which consumer behavior influences were most vital to scenario outcomes, and why.

\section{Fostering Virtual Ethnicity}

The virtual world module offers marketing educators a potentially valuable tool for assessing the aptitude with which students are able to analyze and address consumers' ethnic identity. Clearly, as a digital medium capable of replicating nearly all real world market phenomena, ethnicity is but one of many marketing or consumer behavior constructs that might benefit from proficiency gains. Yet, ethnicity is isolated because of it anthropological and marketing significance for analysis, as well as because of its nascent consideration as a vital virtual world asset. By bridging the common barriers associated with discussions of ethnicity in marketing courses, the virtual world drama allowed students to comfortably traverse the ethnic cultural spectrum with greater fluidity. These instances of "cultural versioning" (Carter 2010) expand the pliability of DuBois' (1903) seminal "double consciousness" thesis beyond African/Americans in White/European environments to encompass all ethnic Americans freely sampling the rich multicultural variety. This virtual world drama contribution of ethnic fluidity also embodies the "content of character" versus "color of skin" tenet of Dr. Martin Luther King Jr. (1963), because students engage avatars from the inside out using the "egg-layers" diagram. In the vernacular of Briley, et al. (2000), the fluidity of virtual avatar identity and interaction (whether dramatic or digital) enables "dynamic versus dispositional" modeling of ethnic culture. 


\section{Factoring in Research Limitations}

Limitations are inevitable in all research and even more so for pedagogical studies. Owing to a less systematically selected student sample and an often restrictive instructional context, pedagogical advances strive to further learning experimentation and evaluation. This study introduces a pedagogical innovation for marketing educators to consider and critique. Knowing the research limitations aids in this constructive improvement process. Four primary types of limitations can be clarified to aid the adoption of virtual world drams, for either raising ethnic consumer behavior aptitude or improve other marketing education competencies:

a) Research Design - The fit between the pedagogical arrangement and the learning purpose of improving skills for analyzing ethnic consumer identity meanings with virtual world market interaction.

b) Research Method - The fit between the pedagogical arrangement and the quality of information collected for analysis.

c) Research Sample - The fit between the learning purpose and the composition of student participants in the study.

d) Research Analysis - The fit between the learning purpose and the techniques for qualitative and quantitative assessment.

The research design is limited by instructional constraints that pose legitimate reasons for substituting a dramaturgy pedagogical arrangement. Of course, a better fit would have been achieved by using the types of immersive digital virtual world platforms that typify the pioneering virtual world marketing education literature. These digital platforms not only accommodate the benefits of dramatic role-play, they permit a more reliable "netnographic" research method for monitoring virtual world participation and analyzing multicultural avatar profiles. Collaborative online metrics associated with digital virtual world platforms have higher information quality for examining both conceptual and multicultural marketing competency.

The study's fairly long duration of four academic quarters provides a credible convenience research sample, without evident biases with respect to the university population. Yet, the findings are less capable of being generalized to other marketing education settings because a widespread stratified random sample was done selected by using a larger and more ethnically diverse sampling frame for representing the online population. Sampling limitations lead to more cautious course adoption and prevent instructional curiosity from becoming a pedagogical commitment among marketing educators. In order to validate "virtual ethnicity," future virtual world dramas must access the vast pool of potential online participants.

Finally, the research analysis supplies necessary findings for exploratory insights but lacks sufficient examination of instructional results. A more rigorous analysis of individual student/avatar profiles would present marketing educators with conclusive proof of learning outcomes. For instance, stronger learning assurance could be provided by statistical techniques such as matched-pairs t-test involving students and avatars, as well as by regression and factor analysis to confirm conceptual marketing competency from "egg-layers diagram" principles and multicultural marketing competency associated with "virtual ethnicity" properties.

\section{AUTHOR INFORMATION}

E. Vincent ("Vince") Carter, Ph.D. is an Associate Professor of Marketing at California State University Bakersfield. He received his Ph.D. in Business Administration \& Marketing from The George Washington University in Washington, DC. Dr. Carter is a nationally recognized marketing educator and researcher with 25 years of experience teaching undergraduate and MBA courses at Historically Black (HBCU), Historically Hispanic Serving (HHSI), and mainstream state research universities. In addition, Dr. Carter's research on marketing pedagogy, innovative marketing course design, online/digital marketing curricula, marketing strategy, and multicultural marketing education appears in several peer-reviewed academic journals and conference proceedings. Those academic publications include, the American Journal Of Business Education, Journal of Education for Business, Journal for Advancement of Marketing Education, AMA Marketing Educators' Conference, Marketing Educators' Association Conference, Marketing Management Association Fall Educators' Conference, and the AMA 
Frontiers in Services Marketing Conference. Dr. Carter has been a primary reviewer for leading marketing textbooks and is a member of the Marketing Management Journal Editorial Review Board.

\section{REFERENCES}

Adams, Gregory (1963), All the World's a Stage. New York: Basic Books.

Anstey, Josephine, Dave Pape, and Dan Sandin (2000), "The Thing Growing: Autonomous Characters in Virtual Reality Interactive Fiction." Virtual Reality, Proceedings of the 2000 IEEE Conference, 71-78.

Atwong, Catherine T., Gayle Vogt, and Irene L. Lange (2002), "The Influence of Ethnicity on Online Learning Experiences. In R. Schlee and J. Schibrowsky (editors), Enabling Technologies and Marketing Education, San Diego, CA: Marketing Educators' Association, April 19 - 21, 53-55.

Baker, Suzanne C., Ryan K. Wentz, and Madison M. Woods (2009), "Using Virtual Worlds in Education: Second Life as an Educational Tool." Teaching of Psychology, 36 (1), 59-64.

Belk, Russell W. and John F. Sherry (2007), Consumer Culture Theory. Amsterdam-Netherlands: Elsevier-Emerald Group Publishing.

Beverland, Michael B. and Fracis J. Farrelly (2010), "The Quest for Authenticity in Consumption: Consumers' Purposive Choice of Authentically Experienced Outcomes.” Journal of Consumer Research, 36 (5), 838 856.

Blackwell, Roger D., Paul W. Miniard, and James F. Engel (2006a), Consumer behavior, $10^{\text {th }}$ edition. Mason, OH: Thomson / South-Western.

Blackwell, Roger D., Paul W. Miniard, and James F. Engel (2006b), "Chapter 11: Culture, Ethnicity, and Social Class." In Consumer behavior, $10^{\text {th }}$ edition. Mason, OH: Thomson / South-Western, 447-462.

Boggs, James G., Amy E. Mickel, and Brooks C. Holtom (2007) "Experiential Learning through Interactive Drama: An Alternative to Student Role Plays." Journal of Management Education, 31 (6), 832-858.

Briley, Donnel A., Michael W. Morris, and Itamar Simonson (2000), "Reasons as Carriers of Culture: Dynamic vs. Dispositional Models of Cultural Influence on Decision Making." Journal of Consumer Research, 27 (2), 157-178.

Brissett, Dennis and Charles Edgley, editors (1990), Life as Theater, $2^{\text {nd }}$ edition. New York: Walter de Gruyter.

Bullen, Arthur Henry (2012), “As You Like It.” In William Shakespeare Complete Plays, New York: Fall River Press, p. 622.

Burton, Dawn (2005), "New Course Development in Multicultural Marketing." Journal of Marketing Education, 27 (2), 151-162.

Burton, Dawn (2002), “Towards a Critical Multicultural Marketing Theory.” Marketing Theory, 2 (2), 207-236.

Buzzard, Christopher, Victoria L. Crittenden, William F. Crittenden, and Paulette McCarty (2011), "The Use of Digital Technologies in the Classroom: A Teaching and Learning Perspective." Journal of Marketing Education, 33 (10), 1-9.

Carter, E. Vincent (2012), "Multicultural Marketing 2.0: The Diffusion of Ethnic Aptitude Pedagogy and Practice." In D. McCabe (Ed.), Proceedings of the Marketing Educators' Association Annual Conference, Long Beach, CA: April $19-21$.

Carter, E. Vincent (2011), "Virtual Ethnicity? Designing a Consumer Avatar Drama to Discover Multicultural Competency." In E. Petkus, Jr., \& S. Cadwallader (Eds.), Crossing Borders in Marketing Education, San Diego, CA: Marketing Educators' Association, April 21 - 23, 123-127.

Carter, E. Vincent (2010), "Deepening Multicultural Marketing Instruction: The Universal and Temporal Dimensions of Ethnic Diversity." Journal for Advancement of Marketing Education, 18 (Summer), 25-37.

Carter, E. Vincent (1997), "Servicescapes in Cyberspace: Service Quality Considerations in Electronically-Mediated Market Environments." In R. Oliver and R. Rust (editors), Proceedings of $6^{\text {th }}$ Annual Frontiers in Services Conference, Nashville, TN, October.

Castronova, Edward (2005), "Real Products in Imaginary Worlds." Harvard Business Review, 83, May, 20-22.

Catterall, Miriam and Pauline Maclaran (2002), Researching Consumers in Virtual Worlds: A Cyberspace Odyssey. Journal of Consumer Behaviour, 1 (3), 228-237.

Costa, Janeen Arnold and Gary J. Bamossy, editors (1997), "Marketing in a Multicultural World: Ethnicity, Nationalism, and Cultural Identity." Journal of Marketing Research, 34 (August), 411 - 412. 
Cova, Bernard and Veronique Cova (2002), "Tribal Marketing: The Tribalisation of Society and Its Impact on the Conduct of Marketing." European Journal of Marketing, Special Issue: Societal Marketing in 2002, 36 (56), $595-620$.

Cova, Bernard, Robert Kozinets, and Avi Shankar (2007), Consumer Tribes. St. Louis, MO: Elsevier.

Cronin, John J. (2009), "Upgrading to Web 2.0: An Experiential Project to Build a Marketing Wiki." Journal of Marketing Education, 31, April, 66-75.

Cui, Geng (2001), "Marketing to Ethnic Minority Consumers: A Historical Journey (1932-1997)." Journal of Macromarketing 21 (1), 23 - 31.

Daniel, Ben, Richard A. Schwier, and Gordon McCalla (2003), "Social Capital in Virtual Learning Communities and Distributed Communities of Practice.” Canadian Journal of Learning and Technology, 29 (3), 113139.

Daugherty, Terry, Hairong Li, and Frank Biocca (2008), "Consumer Learning and the Effects of Virtual Experience Relative to Indirect and Direct Product Experience. Psychology \& Marketing, 25 (7), 568-586.

Denegri-Knott, Janice and Mike Molesworth (2010), "Concepts and Practices of Digital Virtual Consumption." Consumption Markets \& Culture, 13 (2), 109-132.

Deshpande, Rohit, Wayne D. Hoyer, and Naveen Donthu (1986), "The Intensity of Ethnic Affiliation: A Study of the Sociology of Hispanic Consumption.” Journal of Consumer Research, 13 (September), 214 - 220.

Dickey, Michele D. (2003), "Teaching in 3-D: Pedagogical Affordances and Constraints of 3-D Virtual Worlds for Synchronous Distance Learning.” Distance Education, 24 (1), 105-121.

Dinnerstein, Leonard and David M. Reimers (2008), Ethnic Americans. New York: Columbia University Press.

Dou, Wenyu, Boonghee Yoo, and Ma Liangyu (2003), “Consumer Patronage of Ethnic Portals.” Journal of Marketing Education, 26, 50-65.

Drake-Bridges, Erin, Andrew Strelzoff, and Tulio Sulbaran (2011), "Virtual Retail Simulations in Second Life." Marketing Education Review, 21 (2), 125-138.

DuBois, William E. B. (1903), Souls of Black folk. Chicago: A. C. McLurg.

Enright, Allison (2007), "How the Second Half Lives: Marketers are Setting Up Brands in Second Life. Now What?" Marketing News, February 15, 12-14.

Evans, Joel R. (2001), "The Emerging Role of the Internet in Marketing Education: From Traditional Teaching to Technology-Based Education." Marketing Education Review, 11 (Fall), 1-14.

Gibb, S. (2004), “Arts-Based Training in Management Development: The Use of Improvisational Theater.” Journal of Management Development, 23 (7/8), 741-750.

Goffman, Erving (1959), The Presentation of Self in Everyday Life. New York: Doubleday.

Goldberg, D.avid T., editor (1995), Multiculturalism: A Critical Reader, $2^{\text {nd }}$ edition. New York: Wiley-Blackwell.

Grier, Sonia A., Anne M. Brumbaugh, and Corliss G. Thornton (2006), "Crossover Dreams: Consumer Responses to Ethnic-Oriented Products.” Journal of Marketing, 70 (2), 35-51.

Grillo, Ralph D. (2003), "Cultural Essentialism and Cultural Anxiety.” Anthropology Theory, 3 (2), $157-173$.

Grove, S. J., R. P. Fisk, and J. John (2000), "Services as Theater: Guidelines and Implications.” In T. Swartz and D. Iacobucci (editors), Handbook of Services Marketing and Management, Thousand Oaks, CA: Sage, 21-35.

Hansen, David E. (2008), "Knowledge Transfer in Online Learning Environments.” Journal of Marketing Education, 30 (2), 93-105.

Hemp, Paul (2006), “Avatar-Based Marketing.” Harvard Business Review, 84, June, 48-57.

Holzwarth, Martin, Chris Janiszewski, and Marcus M. Newmann (2006), “The Influence of Avatars on Online Consumer Shopping Behavior.” Journal of Marketing, 70 (4), 19-36.

Howe, Neil and William Strauss (2000), Millennials Rising: The Next Great Generation. New York: Random House.

Huffaker, J. S. and E. West (2005), "Enhancing Learning in the Business Classroom: An Adventure with Improv Theater Techniques." Journal of Management Education, 29 (6), 852-869.

Humphreys, Jeffrey M. (2011), The Multicultural Economy 2011 Selig Center for Economic Growth, Terry College of Business, The University of Georgia, Athens, GA..

Jamal, Ahmad (2005), "Playing to Win: An Explorative Study of Marketing Strategies of Small Ethnic Retail Entrepreneurs in the UK." Journal of Retailing and Consumer Services, 12 (1), 1-13.

Jamal, Ahmad (2003), "Marketing in a Multicultural World: The Interplay of Marketing, Ethnicity and Consumption." European Journal of Marketing, 37 (11/12), 1599-1620. 
Jennings, Pamela (1996), "Narrative Structures for New Media: Toward a New Definition." Leonardo: The MIT Press, 29 (5), 345-350.

Jones, Wesley H. (2003), “Over the Wall: Experiences with Multicultural Literacy.” Journal of Marketing Education, 25 (December), $231-240$.

Kaplan Andreas M. and Michael Haenlein (2009), "The Fairyland of Second Life: About Virtual Social Worlds and How to Use Them." Business Horizons, 52 (6), 563-572

Kaplan, Melike D., Burak Piskin, and Beste Bol (2010), "Educational Blogging: Integrating Technology into Marketing Experience.” Journal of Marketing Education, 32 (1), 50-63.

Karreman, Dan (2001), “The Scripted Organization: Dramaturgy from Burke to Baudrillard.” In R. Westwood and S. Linstead (editors), The Language of Organization, London: Sage Press, 89-111.

Kimble, Chris, Paul Hildreth, and Isabelle Bourdon, editors (2008), Communities of Practice: Creating Learning Environments for Educators, 2. Charlotte, NC: Information Age Publishing.

Kirkpatrick, David (2007), "It's Not a Game. The 3-D Online Experience Second Life is a Hit with Users," Fortune, February 5, 56-62.

Klein, Lisa R. (2003), “Creating Virtual Product Experiences: The Role of Telepresence.” Journal of Interactive Marketing, 7 (1), 41-55.

Koslow, Diane R. and Elizabeth P. Salett, editors (2003), Race, Ethnicity and Self: Identity in Multicultural Perspective, $2^{\text {nd }}$ edition. Washington, DC: National Multicultural Institute.

Kozinets, Raymond V. (2006), "Click to Connect: Netnography and Tribal Advertising." Journal of Advertising Research, 46, September, 279-288.

Kozinets, Raymond V. (1999), "E-Tribalized Marketing? The Strategic Implications of Virtual Communities of Consumption.” European Management Journal, 17 (3), 252-264.

Kozinets, Raymond V., Andrea Hemetsberger, and Hope J. Schau (2008), "The Wisdom of Consumer Crowds: Collective Innovation in the Age of Networked Marketing." Journal of Macromarketing, 28 (4), 339-354.

Kritz, Miki and Miri Shonfeld (2012), “Avatars in 3D Learning Environments.” In P. Resta (editor), Proceedings of Society for Information Technology \& Teacher Education International Conference 2012, Chesapeake, VA, 2563-2568.

Laurel, Brenda (1991), Computers as Theater. Reading, MA: Addison-Wesley.

Leberman, Sarah I. and Andrew J. Martin (2005), “Applying Dramaturgy to Management Course Design.” Journal of Management Education, 29 (2), 319-332.

Li, Hairong, Terry Daugherty, and Frank Biocca (2001), "Characteristics of Virtual Experience in Electronic Commerce: A Protocol Analysis.” Journal of Interactive Marketing, 15 (3), 13-30.

Li, Hairong, Terry Daugherty, and Frank Biocca (2002), "Impact of 3-D Advertising on Product Knowledge, Brand Attitude, and Purchase Intention: The Mediating Role of Presence.” Journal of Advertising, 31 (3), 43-57.

Li, Hairong, Terry Daugherty, and Frank Biocca (2003), "The Role of Virtual Experience in Consumer Learning." Journal of Consumer Psychology, 13 (4), 395-407.

Liu, Tsz-Wai, Gabriele Piccoli, and Blake Ives (2007), "Marketing Strategies in Virtual Worlds.” The DATA BASE for Advances in Information Systems, 38 (4), 77-80.

Maclaran, Pauline and Miriam Catterall (2002), "Researching the Social Web: Marketing Information from Virtual Communities.” Marketing Intelligence \& Planning, 20 (6), 319-326.

Martin, Andrew J., Sarah I. Leberman, and James T. Neill (2002), "Dramaturgy as a Method for Experiential Program Design.” The Journal of Experimental Education, 25 (1), 196-206.

Maslow, Abraham H. (1970), Motivation and Personality. New York: Harper and Row.

McGoldrick, Peter J., Kathleen A. Keeling, and Susan F. Beatty (2008), “A Typology of Roles for Avatars in Online Retailing.” Journal of Marketing Management, 24 (3/4), 433-461.

Messinger, Paul R., Eleni Stroulia, and Kelly Lyons (2008), “A Typology of Virtual Worlds: Historical Overview and Future Directions." Journal of Virtual Worlds Research, 1 (1),1-18.

Mich, Claudia C. and Bruce D. Keillor (2011), "Ethnic Identity: Understanding Cultural Differences within a Culture." Marketing Management Journal, 21, 2, 1-9.

Molesworth, Mike (2006), "Real Brands in Imaginary Worlds.” Journal of Consumer Behaviour, 5, July/August), 355-366.

Moore, Dana, Michael Thome, and Karen Haigh (2008), Scripting Your World: The Official Guide to Second Life Scripting.. New York: John Wiley / Sybex. 
Munoz, Caroline K., Natalie T. Wood, and Helene Cherrier (2006), "It's a Small World After All: Cross-Cultural Collaborative Exercises." Marketing Education Review, 16 (1), 53-58.

Negroponte, Nicholas (1995), Being Digital. New York: Alfred A. Knopf.

Nieto, Sonia (1999), "The Light in their Eyes: Creating Multicultural Learning Communities.” Harvard Educational Review, 69 (2), 216-218.

O’Reilly, Norman J., Ryan Rahinel, Mary K. Foster, and Mark Patterson (2007), “Connecting in Megaclasses: The Netnographic Advantage." Journal of Marketing Education, 29 (1), 69-84.

Oswald, Laura R. (1999), "Culture Swapping. Consumption and the Ethnogenesis of Middle-Class Haitian immigrants." Journal of Consumer Research, 25, March, 303-318.

Payan, Janice, James Reardon, and Denny E. McCorkle (2010), “The Effect of Culture on the Academic Honesty of Marketing and Business Students. Journal of Marketing Education, 32 (3), 275-291.

Pearce, Glen (2004), "The Advantages (Benefits) and Disadvantages (Weaknesses) of Educational Drama: Perceptions of Students Studying Marketing at University. International Journal of Management Education, 4 (2), 29-37.

Peltier, James W., William Drago, and John A. Schibrowsky (2003), "Virtual Online Communities and the Assessment of Online Marketing Education. Journal of Marketing Education, 25 (3), 260-276.

Peltier, James W., Amanda Hay, and William Drago (2005), “The Reflective Learning Continuum: Reflecting on Reflection." Journal of Marketing, 27 (3), 250-263.

Pires, Guilherme D. and John Stanton (2005), Ethnic Marketing: Accepting the Challenge of Cultural Diversity. Stamford, CT: Cengage Learning EMEA.

Rao, C. P., editor (2006), Marketing and Multicultural Diversity. Famham Surrey, UK: Ashgate Publishing.

Russell-Bennett, Rebekah, Sharyn R. Rundle-Thiele, and Kerri-Ann Kuhn (2010), "Engaging Marketing Students: Student Operated Businesses in a Simulated World." Journal of Marketing Education, 32 (3), 253-263.

Ryan, Marie-Laure (2001), "Beyond Myth and Metaphor - The Case of Narrative in Digital Media." Game Studies, 1 (1), 1- 13.

Rymaszewski, Michael, Wagner James Au, Mark Wallace, Catherine Winters, Cory Ondrejka, Benjamin BatstoneCunningham, and Philip Rosedale (2006), Second Life: The Official Guide. New York: John Wiley / Sybex, Inc.

Salmon, Gilly (2009), “The Future for (Second) Life Learning.” British Journal of Educational Technology, 40 (3), 526-538.

Schroeder, Ralph (2002), The Social Life of Avatars. New York: Springer.

Sherry, John F. (2000), "Place, Technology and Representation." Journal of Consumer Research, 27, September, 273-278.

Shrivastava, Paul (1999), "Management Classes as Online Learning Communities.” Journal of Management Education, 23 (6), 691-702.

Solomon, Michael R., Natalie T. Wood, Ken Hudson, and Lyle R. Welsch (2009), "Stake Your Claim in the Land Rush of Virtual Worlds: Integrating 'Second Life' into Marketing Education." New Horizons in Marketing Education, 2009 MEA Conference Proceedings, G.H. Brodowsky and R.A. Lupton (editors), 149-152.

Spiller, Lisa D. and Carol Scovotti (2008), "Curriculum Currency: Integrating Direct and Interactive Marketing Content in Introductory Marketing Courses.” Journal of Marketing Education, 30, (April), 66-81.

Stayman, Doug and Rohit Deshpande (1989), "Situational Ethnicity and Consumer Behavior." Journal of Consumer Research, 16, December, 361-371.

Suh, Kil-Soo, Hongki Kim, and Eung Kyo Suh (2011), "What if Your Avatar Looks Like You? Dual Congruity Perspectives for Avatar Use.” MIS Quarterly, 35 (3), 711-729.

Suh, Kil-Soo and Young Eun Lee (2005), "The Effects of Virtual Reality on Consumer Learning: An Empirical Investigation.” MIS Quarterly, 29 (4), 674-697.

Tapscott, Don P., and Anthony D. Williams (2005), Wikinomics: How Mass Collaboration Changes Everything. New York: Penguin-Putnam.

Tikkanen, Henrikki, Joel Hietanen, Thomas Henttonen, and Joonas Rokka (2009), "Exploring Virtual Worlds: Success Factors in Virtual World.” Marketing. Management Decision, 47 (8), 1357-1381.

Tonkin, Elizabeth, Malcolm Chapman, and Maryon McDonald, editors (1989), History and Ethnicity. London: Routledge.

Turkle, Sherry (1997), Life on Screen: Identity in the Age of the Internet. New York: Simon and Schuster. 
Tuten, Tracy (2009), "Real World Experiences, Virtual World Environment: The Design and Execution of Marketing Plans in Second Life." Marketing Education Review, 19 (1), 1-5.

Tuten, Tracy (2010), Enterprise 2.0: How Technology, E-Commerce, and Web 2.0 are Transforming Business Virtually. New York: Praeger.

Tuten, Tracy L., and Michael R. Solomon (2013), Social Media Marketing. Upper Saddle River, NJ: Pearson / Prentice Hall.

Twining, Peter (2010), "Virtual Worlds and Education.” Educational Research, 52 (2), 117-122.

Ueltschy, Linda C. (2001), “An Exploratory Study of Integrating Interactive Technology into the Marketing Curriculum.” Journal of Marketing Education, 23, April, 63-72.

Venkatesh, Alladi (1995), "Ethnoconsumerism: A New Paradigm to Study Cultural and Cross-Cultural Consumer Behaviour.” In J. A. Costa and G. J. Bamossy (editors), Marketing in a Multicultural World, London: Sage Publications, 26-67.

Virtual Learning Curve (VLC) V-Learning 3-D Simulation Courseware Technology. www.vlcglobal.com (accessed July 4, 2012).

Wasko, Molly, Robin Teigland, Dorothy Leidner, and Sirkka Jarvenpaa (2011), "Stepping Into the Internet: New Ventures in Virtual Worlds.” MIS Quarterly, 35 (3), 645-652.

Wenger, Etienne (1998), “Communities of Practice: Learning as a Social System.” Systems Thinker, 9 (5), 1-10. Williams, Jerome D. and William J. Qualls (1989), "Middle-Class Black Consumers and Intensity of Ethnic Identification." Psychology and Marketing, 6 (4), 263-286.

Wood, Natalie T. (2010), "Real Lessons in Virtual Worlds: Using Virtual World Technology to Educate and Train Business Students." In Charles Wankel (editor), Cutting-edge Social Media Approaches to Business Education: Teaching with LinkedIn, Facebook, Twitter, Second Life, and Blogs., New York: Information Age Publishing.

Wood, Natalie T. and Michael R. Solomon (2009), Virtual Social Identity and Consumer Behavior. New York: M. E. Sharpe.

Wood, Natalie T., Michael R. Solomon, and David Allan (2008a), "Welcome to the Matrix: E-Learning Gets a Second Life." Marketing Education Review, 18 (2), 45-53.

Wood, Natalie T., Michael R. Solomon, and Basil G. Englis (2008b), "Personalization of the Web Interface: The Impact of Web Avatars on Users' Responses to E-Commerce Sites." Journal of Website Promotion, 2 (1), 53-69.

Wood, Natalie T., Michael R. Solomon, and Basil G. Englis (2005), "Personalisation of Online Avatars: Is the Messenger as Important as the Message?” International Journal of Internet Marketing and Advertising, 2 (1/2), 143-161.

Wood, Natalie T., Michael R. Solomon, and Basil G. Englis (2003), "No One Looks that Good in Real Life! Projections of the Real Versus Ideal Self in Online Visual Space.” In L. M. Scott and R. Batra (editors), Persuasive Imagery: A Consumer Response Perspective, London: Lawrence Erlbaum, 383-398.

Wood, Natalie T., Michael R. Solomon, Greg W. Marshall and Sarah Lincoln (2010), "Corporate Education Goes Virtual: A Hybrid Approach to Experiential Learning.” In William Ritke-Jones (editor), Virtual Environments for Corporate Education: Employee Learning and Solutions. IGI Global, 284-301.

Wood, Natalie T., Lyle R. Wetsch, Michael R. Solomon and Ken Hudson (2009), "From Interactive to Immersive: Advertising Education takes a Virtual Leap of Faith.” Journal of Advertising Education, 13 (1), 64-72.

Wright, Christine W., Caroline K. Lego, Natalie T. Wood, and Michael R. Solomon (2002), "Cross-Cultural Triangulation Employing an Internet Methodology: Bringing the World Into the Classroom." In R. Schlee and J. Schibrowsky (editors), Enabling Technologies and Marketing Education, San Diego, CA: Marketing Educators' Association, April 19 - 21, 49-52.

Wymbs, Cliff (2011), “Digital Marketing: The Time for a New 'Academic Major' has Arrived.” Journal of Marketing Education, 3 (April), 93-106.

$\mathrm{Xu}$, Jing, Soyeon Shim, Sherry Lotz, and David Almeida (2004), "Ethnic Identity, Socialization Factors, and Culture-Specific Consumption Behavior.” Psychology and Marketing, 21 (2), 93 - 112.

Yankelovich, Inc. (2011), Yankelovich MONITOR Multicultural Marketing Study. Raleigh, NC.

Yoo, Boonghee and Naveen Donthu (2002), "The Effects of Marketing Education and Individual Cultural Values on Marketing Ethics of Students.” Journal of Marketing Education, 24 (2), 92-103. 


\section{NOTES}

